\title{
Identified Human Factors in Knowledge Management in the Context of Knowledge Sharing
}

\author{
Oyelami Julius Olusegun ${ }^{1}$,Azleena Mohd Kassim² \\ ${ }^{1,2}$ Universiti Sains Malaysia, School of Computer Science, Penang 11800 Malaysia \\ 2azleena.mk@usm.my
}

Article History: Received: 10 November 2020; Revised: 12 January 2021; Accepted: 27 January 2021; Published online: 05 April 2021

\begin{abstract}
With the present and advances in information and communication technology (ICT), sharing knowledge across organisations has become easier and feasible. However, knowledge sharing has been a complex phenomenon over the years and identifying factors that influence knowledge sharing (KS) across organisation has becomes crucial and critical in the recent days. This paper review the effect of culture and behavioural differences as a human factors and the knowledge management practices needed to improve KS in organisations. Data were collected from 7 experts and 50 personnel by questionnaire. The result from the statistical data analysis revealed 15.67 and 3.96 as variance and standard deviation on culture respectively. The variance on behaviour is 8 and its standard deviation is 2.83 , this indicate weakness in KS therefore, there is a presence of non- sharing culture and behaviour that discourage knowledge sharing. The findings from this pilot study suggest that, a centralised knowledge management structure without effective human practice towards its policies of sharing, coordination and distribution of knowledge in the context of knowledge management towards knowledge sharingmight fail. For organisation to avoid knowledge holding (KH) and knowledge risk (KR), a mechanism like knowledge sharing strategic implementation plan (KSSIP) can be used as a solution.

Keywords: Human Factors, Knowledge sharing, Knowledge Management
\end{abstract}

\section{Introduction and Related Works}

Researchers over the year have tried to establish working definitions for knowledge sharing (KS) with no one accepted standard due to its complexity. The implementations of effective KS strategies still play enormous roles in organisation today (Zahidul et al.,2018). In the literature, KS has been defined in so many ways, one of the ways is the ability to conduct the exchange knowledge among federal, state, local, territorial, tribal levels and across different levels of organisation and the private sector (Singh and Rao,2018;Isfahani, et al., 2013; Yusefi, et al., 2011).

This capability of sharing includes the routine sharing as well as issuing of levels of agreement to organisation and the private sector in preparation for, and in response to events and incidents in sharing (Fleming, 2012; Gantasala and Larisa, 2018; Omotayo, 2015; Alexandra, et al., 2019). Knowledge sharing represents the process through which knowledge are provided by one entity to one or more other entities to facilitate working operation and decision-making under conditions of uncertainty, where knowledge sharing represents information and its meaning (Weijs-Perrée et. al., 2019; Dust and Zieba, 2019).

The argument by Alexander, et al. (2019) is similar to the argument put forward by Manzoor et al. (2019) and Dust and Zieba (2019), that the decision-making process need knowledge sharing to represent goal-directed behaviour in the presence of options. It is also reported by researchers that uncertainty represents the state of being uncertain, effective knowledge sharing will enable the organisation to come to a conclusive and positive results, adding that, knowledge holding $(\mathrm{KH})$ will lead the organisation to knowledge risk (KR) (Stam et al., 2014; Nodari, et al., 2016; Manzoor et al., 2019; Dust and Zieba, 2019). This statement is in agreement with the statement put forward in the work of Alexandra,et. al. (2019) and Minou, et al. (2019).

Rafique et al. (2018), Rajabion et al. (2019), and Zahidul et al. (2018) extended the works of Cummings (2004), Constant et al. (1994), Courtright (2007), Delong (1997) and Alvai et al. (2006), where they maintained that knowledge sharing should be goal-directed and should be shared among entities who can affect the purposes of achieving goals and that knowledge sharing should also be fit for reducing uncertainty. In a similar argument, the Centre for Advance Researches in Language Acquisition (CARLA) disagreed that knowledge sharing cannot reduce all uncertainty, it may sometime increase it, if not shared properly (CARLA, 2012).

Recent studies have shown that diversity in behaviour and culture brought uncertainty as well as challenges in knowledge sharing within organisation, as diversity in culture is seen as impeding factor towards sharing (Al Saififi et al., 2016;Appel-Meulenbroek et al., 2017; Hussain et al., 2017; Singh and Rao, 2018). This statementis also supported by Iram and Ali (2018), Zahidul et al. (2018), Anupam et al. (2018); Hussain et al., (2016) and 
Weijs-Perrée et. al. (2019) where they have also taken into account of people in the exchange of information, knowledge and data between various organisations and department. Therefore, organisation must establish a common ground for effective sharing. In this paper, it is postulated that knowledge sharing can be more effective for decision-making if diverse cultures and behavioural difference are addressed in knowledge management for the context of KS.

\section{Data Analysis and Interpretation}

Questionnaires are distributed among the management and the general staff of XYZ organisation. XYZ is a manufacturing organisation located in West Africa. The organisation was selected based on its cultural diversity and different ethnic groups working with this organisation. The questionnaire was distributed to 57 respondents and the questionnaire comprises of 14 questions that focus on culture and behaviour. The target respondents comprised of (1) IT Manager, (2) Chief Information Officer (CIO), (3) Financial Information Officer(FIO), (4) Human Resource Manager, (5) Accounting Manager, (6) Production manager, (7) Quality control officer and (8) Business Continuity Analyst (Who conduct business case and analysis annually) and those from the middle level management. We consider this people as the organization leaders who could have access to and contribute to this study.

There are 14 questions in the questionnaire, the first set of the question focused on cultural questions. This question is tagged as data-set A, while the second set of the questionnaire focus on behavioural questions, tag data-set $\mathrm{B}$. Table 1 and Table 2 shows the frequency of responses to the questions data-set $\mathrm{A}$ and data-set $\mathrm{B}$ respectively. The questionnaire that form Data set A and B consist confidential and highly sensitive questions many respondents do not want to reveal about the organisation due to its sensitivity, therefore, the unattempted questions are left out from the data entry. This was considered as a limitation to this study, as limited data are used to conclude the finding in this pilot study.

Figure 1 and 2, further depict how strongly culture and behaviour difference has affected knowledge sharing in knowledge management for the context of KS. The bar chart in Figure 1 and 2, further explain the effect of culture and behavioural differences in the sharing of information in the context of knowledge management.

Table 1.Showing the data entry for questionnaires base on Culture (Data Set A)

\begin{tabular}{|l|l|l|l|l|l|l||l|}
\hline Level of Agreement & Q1 & Q2 & Q3 & Q4 & Q5 & Q6 & Q7 \\
\hline Strongly Agreed & 22 & 16 & 16 & 18 & 22 & 17 & 19 \\
\hline Agreed & 3 & 11 & 10 & 11 & 9 & 5 & 10 \\
\hline Neither Agreed nor Disagreed & 4 & 1 & 5 & 2 & 1 & 3 & 1 \\
\hline Disagreed & 2 & 0 & 1 & 0 & 2 & 0 & 1 \\
\hline Strongly Disagreed & 0 & 0 & 0 & 1 & 0 & 0 & 0 \\
\hline Total & 31 & 28 & 38 & 32 & 35 & 25 & 31 \\
\hline
\end{tabular}

Note: Q Stand for Question

Table 2.Showing the data entry for questionnaires base on Behaviour (Data Set B)

\begin{tabular}{|l||l||l||l|l|l||l|l|}
\hline Level of Agreement & $\begin{array}{l}\text { Q } \\
8\end{array}$ & Q9 & Q10 & Q11 & Q12 & Q13 & Q14 \\
\hline Strongly Agreed & 20 & 15 & 10 & 8 & 20 & 10 & 35 \\
\hline Agreed & 3 & 6 & 5 & 6 & 8 & 10 & 0 \\
\hline $\begin{array}{l}\text { Neither Agreed nor Disagr } \\
\text { eed }\end{array}$ & 4 & 2 & 5 & 2 & 1 & 5 & 0 \\
\hline Disagreed & 1 & 2 & 4 & 4 & 1 & 2 & 0 \\
\hline Strongly Disagreed & 0 & 1 & 4 & 8 & 1 & 0 & 0 \\
\hline Total & 28 & 26 & 28 & 28 & 31 & 27 & 35 \\
\hline
\end{tabular}

Table 3 and Table 4 further present the statistical data analysis of the data obtained from data-set A and data-set B as shown. The results shows in Table 1 that, out of 57 potential respondents, only 31 attempted Q1, 28 attempted Q2,38 attempted Q3, 32 attempted Q4, 35 attempted Q5, 25 attempted Q6 and 31 attempted Q7. In 
Table 2, Q8, Q9, Q10, Q11 are answered with 28, 26, 28, and 28 respondents respectively while Q12, Q13 and Q14 are answered with 31,27 , and 35 respondents.

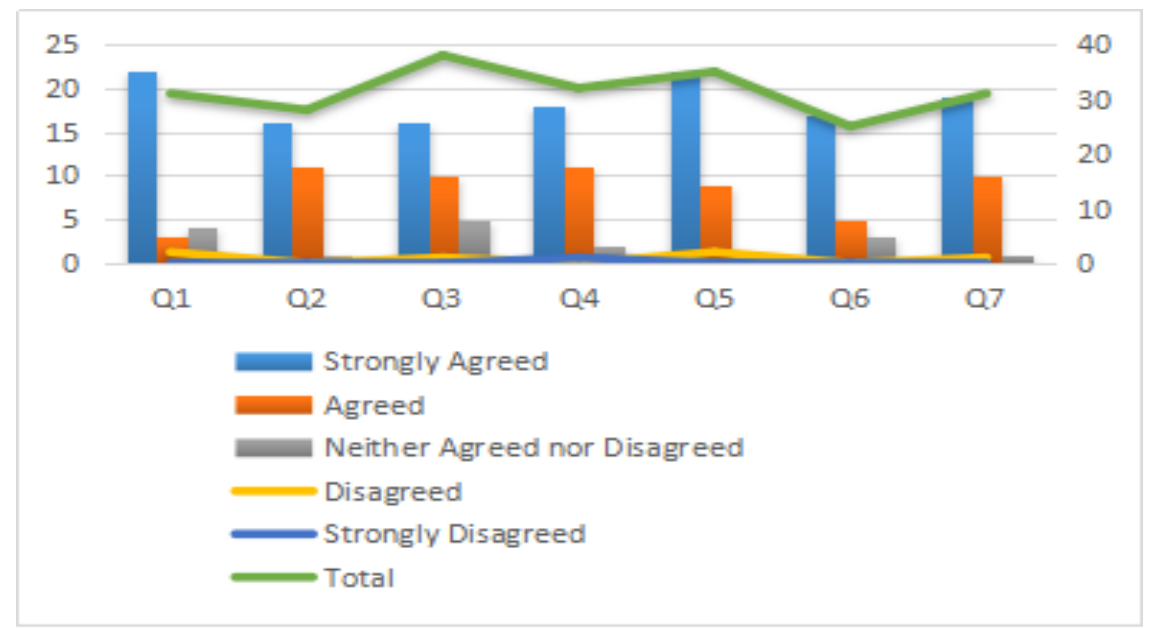

Figure 1.Analysis for questionnaire base on Culture (Data Set A)

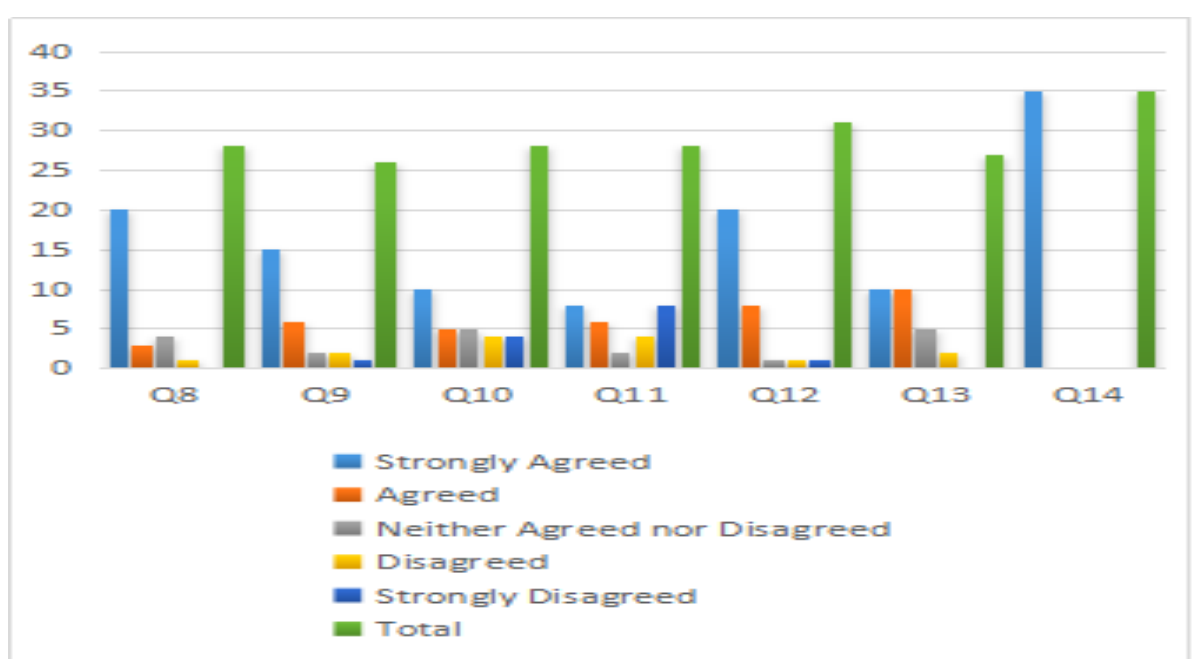

Figure 2.Analysis from questionnaire base on Behaviour (Data Set B)

The variance and standard deviation values for data-set A and B are 3.95897 and 2.82843 respectively. In Table 3 and Table 4, there is an indication that, cultural and behavioural differences have mitigating effects on the organisation knowledge sharing. Culture and behavioural differences might be a contributing human factor in knowledge sharing in the context of knowledge management, in this regard, there would be knowledge holding $(\mathrm{KH})$ that resulted to knowledge risk $(\mathrm{KR})$ among employees working together. The data also suggest that there is no encouraging culture and behaviour towards sharing, therefore, $\mathrm{KH}$ and $\mathrm{KR}$ become inevitable and create negative impact to the organisation knowledge assets.

Table 3.Statistical data analysis on data set A (Culture)

\begin{tabular}{|l|l|l|}
\hline Scores & Deviation (X-M) & Squared Deviation \\
\hline 31 & -0.43 & 0.18 \\
28 & -3.43 & 11.76 \\
38 & 6.57 & 43.18 \\
32 & 0.57 & 0.33 \\
35 & 3.57 & 12.76 \\
25 & -6.43 & 41.33 \\
31 & -0.43 & 0.18 \\
M: $\mathbf{3 1 . 4 3}$ & & \\
\hline
\end{tabular}

$\mathrm{N}: 7$

M: 31.43 
SS: 109.71

$\sigma 2=\mathrm{SSN}=109.71 / 7=15.67$

$\sigma=\sqrt{ } \sigma 2=\sqrt{ } 15.67=3.96$

Variance $=15.67347$.

Standard Deviation $=\mathbf{3 . 9 5 8 9 7}$.

Table 4.Statistical data analysis on data set B (Behaviour)

\begin{tabular}{|l|l|l|}
\hline Scores & Deviation (X- M) & Squared Deviation \\
\hline 28 & -1 & 1 \\
26 & -3 & 9 \\
28 & -1 & 1 \\
28 & -1 & 1 \\
31 & 2 & 4 \\
27 & -2 & 4 \\
35 & 6 & 36 \\
M: 29 & & SD: $\mathbf{5 6}$ \\
\hline
\end{tabular}

$\mathrm{N}: 7$

M: 29

SD: 56

$\sigma 2=\mathrm{SSN}=56 / 7=8$

$\sigma=\sqrt{ } \sigma 2=\sqrt{ } 8=2.83$

Variance $=8$.

Standard Deviation $=\mathbf{2 . 8 2}$

\section{Recommendation}

Based on data generated and its analysis, this pilot study recommend that, organisationshould focus onidentifying and developing rules for knowledge sharing (KS),organisation should define minimum requirements for KS for the purpose of developing and maintaining knowledge towards sharing by establishing knowledge sharing strategic implementation plan (KSSIP) as a mechanism. The minimum requirements for KSSIP should include the following elements but are not limited to: (i) when knowledge should be shared (ii) who is authorized to receive the knowledge (iii) who is authorized to share knowledge (iv) what types of knowledge can be shared. This will enable the organisation to effectively managed and plan KS by improving management towards strategic planning that will discourage withholding of knowledge (e.g. knowledge holding) and implement adequate training and awareness on the impart of culture and behaviour on sharing knowledge to avoid or mitigate knowledge risk (KR).

\section{Discussion and Conclusion}

Enhancing culture and behaviour in knowledge sharing by reducing human factors is inevitable to all organisations (Weijs-Perréeet. al., 2019) and (Islam et al., 2016). It is believed that culture have been developed to empowers employees to break down barriers, rather than be protectionist (Singh and Rao, 2018). The direction for this should come from the top management (Yusefi, et al., 2011).

Developing a culture and behaviour that rewards knowledge sharing is paramount in organisation and implement knowledge sharing strategic implementation plan (KSSIP) that focus on human factor. It will enable organisation to monitor changing in behaviour and changing and enhance culture and behaviour to one that naturally encourages the responsible sharing of knowledge that is fundamental to organisation success. Training must also be provided to increase the emphasis on the responsibility to provide knowledge sharing culture and behaviour. By promoting mechanisms such as KSSIP as a strategy for sharing knowledge it may remove obstacles and welcome better relationship among knowledge management users in the context of knowledge sharing for organisation success. This strategy requires good human relationship in the development and execution of the KnowledgeSharing StrategicImplementationPlan (KSSIP) that will be a unified and coordinated set of initiative for successful KS. This article proposed KSSIP focusing on human factor. This solution enhances sharing of knowledge and as a strategy, it encourages knowledge owners in sharing their knowledge (e.g tacit or explicit) with the organisation and to avoid $\mathrm{KH}$ and $\mathrm{KR}$. In the future, researchers might begin to look into KS by considering the aspect of human psychology that will focus on human instinct to sharing and willingness of given out their knowledge, the mode of happiness and the factors that might contribute and enhance human 
happiness towards knowledge sharing without barrier or obstacles. For organisation to avoid KH and KR a mechanism like KSSIP can be used as a solution.

\section{Acknowledgement}

This research article is supported by the Short Term Grant, Universiti Sains Malaysia.

\section{References}

1. Alexandra Zbuchea, FlorinaPînzaru, MihailBusu, Sergiu-Octavian Stan and AlinaBârgăoanu (2019). Sustainable Knowledge Management and Its Impact on the of Biotechnology Organizations. Journal of Sustainability. Sustainability. 11,359.

2. Appel-Meulenbroek, H. A. J. A., de Vries, B., and Weggeman, M. C. D. P. (2017). Knowledge sharing behavior: The role of spatial design in buildings. Environment and Behavior, 49(8), 874-903.

3. Al Saififi, S. A., Dillon, S., and McQueen, R. (2016). The relationship between face to face social networks and knowledge sharing: An exploratory study of manufacturing firms. Journal of Knowledge Management, 20(2), 308-326.

4. Anupam Kumar Das; Li Yi and Md. Aftab Uddin (2018). Knowledge withholding in sharing knowledge within an organisation: the shadowy impediment in spreading innovation. International Journal of Knowledge Management Studies, 2018 Vol.9 No.4, pp.381 - 402.

5. Alvai, M., Leidner, D.E and Kayworth, R.T. (2006). An empirical examination of the influencesof organizational culture on knowledge sharing. Journal of ManagementInformation systems. 22(3): 191-224.

6. Centre for Advance Researches in Language Acquisition (2012). Diversity in languages ans cultures. University of Minnesota. USA: CARLA Inc.

7. Cummings, J.N. (2004). Work groups, structural diversity, and knowledge sharing in a global organization. Journal of Management Science, Vol. 50, (3), 352-364.

8. Constant, D., Kiesler S., and Sproull L. (1994). A study of attitudes aboutinformationsharing, An Information Systems Research. Journal of Human Psychology. Vol. $5 \quad$ (No. 4) 400-421.

9. Courtright, C. (2007). Context in information behavior research. Annual Review ofInformation Science and Technology. Journal of Human integration and behavior. Vol 200, (76), 41-47.

10. Delong, D. 1997. Building The Knowledge-Based Organization: How Culture Drives Knowledge Behaviors. Working Paper, Ernst \& Young's Center for BusinessInnovation. Boston.

11. Gantasala V. Prabhakar; Larisa A. Savinkina (2018). Knowledge conversion processes and organisational performance. International Journal of Knowledge Management Studies, 2018 Vol.9 No.4, pp.342 - 362 .

12. Hussain, A., Mkpojiogu, E.O.C., Almazini, H., Almazini, H. (2017). Assessing the usability of Shazam mobile app. AIP Conference Proceedings, 1891, art. no. 020057.

13. Hussain, A., Mkpojiogu, E.O.C., Yusof, M.M. (2016). Perceived usefulness, perceived ease of use, and perceived enjoyment as drivers for the user acceptance of interactive mobile maps. AIP Conference Proceedings, 1761, art. no. 020051.

14. Isfahani, A.N., Nilipour,A., Aghababapour, T., Tanhaei, M.H. (2013): Studying the Impart of Artititude towards Knowledge Sharing on Employee's Hapiness. International Journal of Academic Research in Business and Social Science, Vol. 3, No 4, ISSN: 2222-6990

15. IramMushtaq; Ali Rizwan, (2018). Obstacles to knowledge sharing in engineering organisations: a quantitative approach.International Journal of Knowledge Management Studies, 2018 Vol.9 No.3, pp.293 - 307.

16. Islam, R., Ghani, A.B.A., Kusuma, B., Theseira, B.B. (2016). Education and human capital effect on Malaysian economic growth. International Journal of Economics and Financial Issues, 6 (4), pp. 1722-1728.

17. MinouWeijs-Perrée, RianneAppel-Meulenbroek and Theo Arentze (2019): Analysing knowledge sharing behaviour in business centres: a mixed multinomial logit model, Knowledge Management Research and Practice, DOI:

10.1080/14778238.2019.1664269

18. ManzoorUlAkram, ChetnaChauhan,KoustabGhosh, and Amol Singh (2019). Knowledge Management, Sustainable Business Performance andEmpowering Leadership: A Firm-Level Approach. International Journal of KnowledgeManagement. DOI: 10.4018/IJKM.2019040102

19. Omotayo, F.O. (2015). Knowledge Management as an important tool in Management: A Review of Literature. Libr. Philos. Pr. 2015, 1, 1-23. 
20. Rajabion, L., Sataei Mokhtari, A., Khordehbinan, M., Zare, M. and Hassani, A. (2019), "The role of knowledge sharing in supply chain success", Journal of Engineering, Design and Technology , Vol. ahead-of-print No. ahead-of-print. https://doi.org/10.1108/JEDT-03-2019-0052

21. Rafique, M., Hameed, S. and Agha, M. (2018), "Impact of knowledge sharing, learning adaptability and organizational commitment on absorptive capacity in pharmaceutical firms based in Pakistan", Journal of Knowledge Management, $\quad$ Vol. $22 \quad$ No. $1, \quad$ pp. 44-56. https://doi.org/10.1108/JKM-04-2017-0132

22. Singh Pooja K and Rao M.K.,(2018) Examining the effect of KM strategy on knowledgeperformance:the mediating role of sharing behaviour and enablers. International journal of knowledge management studied, 2018 Vol.9 No.4, pp.309 - 324.

23. Susanne Durst and MalgorzataZieba, (2019). Mapping knowledge risks: towards a betterunderstandingof knowledge management. Journal of knowledge management research and practice,2019, vol. 17, no. 1, 1-13.

24. Stam, W., Arzlanian, S., and Elfring, T. (2014). Social capital of entrepreneurs and small firm performance; A meta-analysis of contextual and methodological moderators. Journal of Business Venturing, 29, 152-173.

25. Yusefi, S., Moradi, M., Tishevarz, M.K., (2011). Role of Employees' Organization Commitment in Knowledge sharing. Human Development. $7^{\text {th }}$ year, 30, pp 23-35

26. Zahidul Islam; Sajjjad M. Jasimuddin; IkramulHasan, (2018). Determinants that influence knowledge sharing: an integrated literature review. International Journal of Knowledge Management Studies, 2018 Vol.9 No.4, pp.363 - 380 